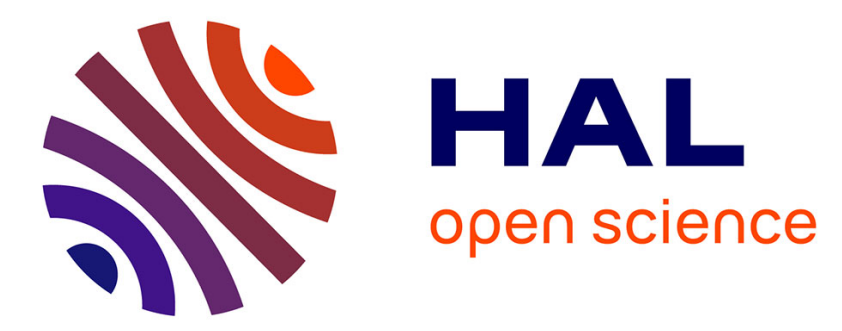

\title{
Nanoindentation of wet and dry compact bone: influence of environment and indenter tip geometry on the indentation modulus
}

\author{
Griselda María Guidoni, Michael Swain, Ingomar Jäger
}

\section{To cite this version:}

Griselda María Guidoni, Michael Swain, Ingomar Jäger. Nanoindentation of wet and dry compact bone: influence of environment and indenter tip geometry on the indentation modulus. Philosophical Magazine, 2010, 90 (05), pp.553-565. 10.1080/14786430903201853 . hal-00560312

\section{HAL Id: hal-00560312 \\ https://hal.science/hal-00560312}

Submitted on 28 Jan 2011

HAL is a multi-disciplinary open access archive for the deposit and dissemination of scientific research documents, whether they are published or not. The documents may come from teaching and research institutions in France or abroad, or from public or private research centers.
L'archive ouverte pluridisciplinaire HAL, est destinée au dépôt et à la diffusion de documents scientifiques de niveau recherche, publiés ou non, émanant des établissements d'enseignement et de recherche français ou étrangers, des laboratoires publics ou privés. 


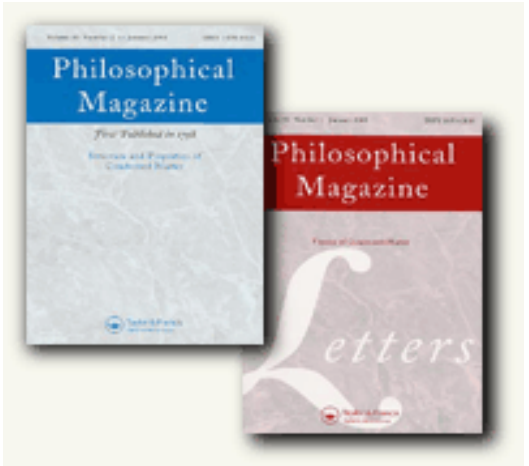

\section{Nanoindentation of wet and dry compact bone: influence of environment and indenter tip geometry on the indentation modulus}

\begin{tabular}{|c|c|}
\hline Journal: & Philosophical Magazine \& Philosophical Magazine Letters \\
\hline Manuscript ID: & TPHM-09-Feb-0069.R1 \\
\hline Journal Selection: & Philosophical Magazine \\
\hline $\begin{array}{r}\text { Date Submitted by the } \\
\text { Author: }\end{array}$ & 22-Jun-2009 \\
\hline Complete List of Authors: & $\begin{array}{l}\text { GUIDONI, Griselda; Austrian Academy of Sciences, Erich Schmid } \\
\text { Institute; University of Leoben, Materials Physics Department } \\
\text { Swain, Michael; University of Sydney, Biomaterials Science } \\
\text { Research Unit; United Dental Hospital, Faculty of Dentistry } \\
\text { JÄGER, Ingomar; University of Leoben, Materials Physics } \\
\text { Department }\end{array}$ \\
\hline Keywords: & $\begin{array}{l}\text { biological materials, composite materials, elasticity, mechanical } \\
\text { behaviour, nanoindentation }\end{array}$ \\
\hline Keywords (user supplied): & compact bone, Hank's balanced salt solution \\
\hline
\end{tabular}

\section{scholarONE" \\ Manuscript Central}




\title{
Nanoindentation of wet and dry compact bone: influence of environment and indenter tip geometry on the indentation modulus
}

\author{
G. Guidoni $^{\mathrm{a} *} ;$ M. Swain ${ }^{\mathrm{b}}$ and I. Jäger ${ }^{\mathrm{c}}$.
}

a. Erich Schmid Institute of Materials Science, Austrian Academy of Sciences and Department of Materials Physics, University of Leoben, Leoben, Austria ; ${ }^{b}$ Biomaterials Science Research Unit, Faculty of Dentistry, University of Sydney, United Dental Hospital, Sydney, Australia; ${ }^{c}$. Department of Materials Physics, University of Leoben, Leoben, Austria

a. Erich Schmid Institute of Materials Science, Austrian Academy of Sciences and Department of Materials Physics, University of Leoben. Postal adress: Jahnstr. 12, Leoben, A-8700, Austria.

Phone: + 433842804 215. Fax: + 433842804 116. Email: griselda.guidoni@notes.unileoben.ac.at. Corresponding author.

b. Biomaterials Science Research Unit, Faculty of Dentistry, University of Sydney, United Dental Hospital. Postal adress: Surry Hills NSW 2010, Sydney, Australia. Phone: +61 29351 1814. Email: mswain@mail.usyd.edu.au.

c. Department of Materials Physics, University of Leoben. Postal adress: Jahnstr. 12, Leoben, A8700, Austria. Phone: +433842804 108. Fax: + 433842804 116. Email:

ingomar@unileoben.ac.at.

\footnotetext{
* Corresponding author: E-mail: griselda.guidoni@ notes.unileoben.ac.at
} 
The indentation derived elastic modulus, E, of bovine compact bone was obtained by means of nanoindentation. The indentation modulus of the dry condition (i.e. under atmospheric conditions) is 40 $\%$ higher than when measured wet (i.e. immersed in buffer solution). Although this difference is independent of orientation, there is a $20 \%$ difference in indentation modulus within the same tested environment between longitudinal and transversal directions. In addition, the estimated indentation modulus of the same samples when tested wet in buffer solution after deep freezing $\left(-15^{\circ} \mathrm{C}\right)$ was not affected. The discrepancy between wet and dry results was attributed to the non mineralized phase contribution and rationalized by a simple mechanical model [1]. Anisotropy effects could be explained in terms of deformation mechanisms with orientation. The effect of frozen storage temperatures may be clarified considering the biomechanics of the helicoidal arrangement of lamellar bone. Viscoelastic effects were also considered and incorporated into the analysis of the force-displacement data. Keywords: compact lamellar bone; nanoindentation; Hank's balanced salt solution. 
Collagen fibrils are organized in a staggered way [3]. The mineralized collagen fibre of about $100 \mathrm{~nm}$ in diameter is composed of bundles of mineralized fibrils embedded in an extra cellular matrix. The mineral individual nano-crystallites are generally assumed to be platelets elongated along the $\mathrm{c}$ axis. Collagen behaves visco-elastically whereas hydroxyapatite is a brittle ceramic. The small size of the mineral crystals is thought to impart theoretical strength [4] to their structure.

The mechanical properties of a composite material depends not only on the composition, but also on the microstructure arrangement [5]. Compact bone lamellae consist of an extra-fibrillar matrix with collagen fibres interweaving each other running in longitudinal, transverse, and various oblique directions [6]. Due to the young age of the sample investigated, the bone is of the fastgrowing type as described by, e.g., [2], i.e. fibrolamellar bone, consisting of lamellar bone sheathing the blood vessels and other canaliculi, alternating with layers of woven or parallel-fibered bone (termed woven bone in the following for the sake of brevity). The structural difference between those two is that lamellar bone grows slower, but is better ordered, with its lamellae, and the mineralized collagen fibres within, oriented preferentially parallel to the long axis of the bone (the main stress direction), whereas woven bone is laid down faster, is much more disordered, but sometimes more highly mineralized. Due to the young age, no secondary osteons ("Haversian systems") are expected to be present. 
Although a detailed quantitative description of the deformation mechanisms of bone at the nanoscale remains unclear, several mechanisms have been proposed [1, 7-9]. In addition, the influence of the environment on the mechanical properties of compact bone is still not well understood.

Jäger and Fratzl [1] proposed a model with a staggered array of platelets that accounts for an increase of both elastic modulus and fracture stress with the amount of mineral in the fibril. This latter model includes shear stresses localised in the collagen phase between the overlapping mineral platelets. Some of the limitations of this model are that the stress must occur along the main axis of the mineral phase and the minerals are considered to be highly oriented. Gupta et al. [9] noted that this model could be applied to the next higher hierarchical level where the mineral phase and the organic phase arranged together into fibres (or fibrils) embedded in a ductile matrix.

Several authors reported moisture dependent properties of compact bone [9-12], however the origin of such differences and the contribution of the involved hierarchical level on the measured total mechanical property of lamellar bone (excluding the vascular and lacuno-canalicular porosity) is still not well understood. Bushby et al. [12] carried out a comparison between dry (replacing unbound water with different grades of ethanol), wet (immersed in a synthetic cartilage lymph, SCL) and embedded in PMMA for specimens of 2 year old horse compact bone. They found that there was a 10 to $30 \%$ increase of indentation modulus from wet to dry conditions and that embedding the samples in PMMA does make a difference in the measured properties. They based their discussion on the influence water had on the mechanical properties. The present investigation is an attempt to extend the understanding of the deformation mechanisms by also considering the influence of composition and microstructural arrangement on the response of compact lamellar bone. 
The aim of this paper is to develop an understanding of the mechanisms associated with nano-indenting lamellar compact bone. The influence of temperature of storage and environment were investigated. A rounded diamond conical indenter tip of $90^{\circ}$ included angle and approximately $1200 \mathrm{~nm}$ nominal radius was used. This particular indenter tip shape was chosen for its rotational symmetry avoiding indenter tip orientation effects and singularity effects associated with a sharp tip. Initially the contact follows an elastic response predicted by Hertz [19] before the onset of elastic-plastic behaviour. Once the rounded tip portion of the truncated cone (at $\sim 350 \mathrm{~nm}$ depth) is overcome a condition of effective constant contact strain prevails for further indentation penetration depths [20].

\section{Sample preparation}

A femur of a 1.5 years old steer was obtained from a butcher on the same day of slaughtering. It had been refrigerated (stored at a temperature above zero) but never frozen. It had been dissected from the muscle just prior to purchase. It was immediately taken to the laboratory and prepared for testing and storage. The soft tissue was removed with a scalpel and the bone marrow was taken away with high pressure air. The cleaned compact bone parts were kept in the refrigerator at $4^{\circ} \mathrm{C}$ immersed in Hank's balanced salt solution (HBSS) with $0.1 \mathrm{wt} \%$ of sodium azide $\left(\mathrm{NaN}_{3}\right.$, Merck 888) as an antibacterial. The above storage conditions have been shown to retain the integrity of 
dentin for more than two years of storage [21]. In addition, the samples were never frozen before commencing the investigation.

Three main testing directions were defined: longitudinal (L), transversal (T) and radial (R). A schematic is presented in (Figure 1). 1. Thus, the nomenclature was chosen as follows; BL for the bovine compact bone sample tested parallel to the longitudinal direction and BT for the bovine compact bone sample tested in the transversal direction.

Two pieces of approx. $8 \times 8 \mathrm{~mm}^{2}$ were cut with a saw along the longitudinal direction of the diaphysis a short time after receiving the bovine bone. One of them was prepared leaving the cross section exposed for testing (BL) and the other one the transversal section (BT).

The exposed area of the compact bone pieces was ground and polished to a $2500 \mathrm{P}$ grit finish with silicon carbide cloths, followed by polishing using $0.3 \mu \mathrm{m}$ alumina suspension. The final thickness of the sample was $2 \mathrm{~mm}$. In the case of 'wet' conditions, the sample was continuously rinsed with HBSS while polishing, and stored under HBSS at all times to avoid accidental dehydration.

The tested bovine samples, when not under investigation, were always kept at $4{ }^{\circ} \mathrm{C}$ immersed in HBSS. The first experiments, on both for BL and BT samples, were done in a wet condition. Once the sample was tested wet, the buffer solution was removed with a syringe; and the sample was wiped with a tissue paper and left to dry under laboratory conditions for more than $48 \mathrm{~h}$ and tested dry. The samples were then again immersed in HBSS and stored at $-15^{\circ} \mathrm{C}$ for at least 12 hours. They were subsequently laboratory thawed over at least 8 hours and tested wet at room temperature. "FR" was added to the nomenclature to distinguish this new storing condition. 


\section{Nanoindentation Tests}

Nanoindentation tests were carried out using an add-on nanoindentation device (Hysitron Triboscope, Hysitron Inc., Minneapolis, MN, USA) mounted on the scanner head of an AFM stage (Veeco - Digital Instruments, Santa Barbara, CA, USA).

Two kinds of configurations were tested: 'dry indentations', in which the samples were stored and indented under atmospheric conditions, and 'wet indentations', in which the sample and part of the indenter were immersed in HBSS during testing. For both cases the same indenter, mounted at the end of a tungsten rod ca. $9.5 \mathrm{~mm}$ long was used.

The indenter tip area function was calibrated with a fused quartz sample. Although the penetration depths during calibration are governed by the nature of the standard sample (fused quartz), the form of the area function is chosen to converge to the ideal area of the indenter at higher penetration depths [22].

Nanoindentation tests were carried out in several loading-unloading steps: first the specimen was loaded at a constant loading rate to the maximum load $(5000 \mu \mathrm{N})$ in 5 seconds, secondly the load was maintained 60 seconds in order to exhaust most of the creep before unloading, thirdly the sample was unloaded at a linear rate to an intermediate load of $1000 \mu \mathrm{N}$ within $10 \mathrm{~s}$, fourthly this intermediate load was held for $20 \mathrm{~s}$ to monitor recovery effects and, finally, complete linear unloading within $2 \mathrm{~s}$. Testing in all cases was at room temperature.

Indentation modulus, $\mathrm{E}$, and hardness, $\mathrm{H}$, were calculated by means of the loaddisplacement curves using the well known Oliver-Pharr [23] method. However, when indicated, the elastic modulus of the sample was derived using a Poisson's ratio of 0.3 . 
At least 15 measurements per condition were taken. The location for each nanoindentation was chosen by means of AFM imaging, done with the same indenter tip. The indentations were placed specifically in lamellar bone.

\section{Results}

Fig 2 shows a 3D projection of a BL sample taken by scanning the nanoindenter tip on the sample at a $1 \mu \mathrm{N}$ load. Two osteons are observed in the lower part. In addition, five indents located inside one lamella can be seen. The indents were placed manually in the desired positions, limiting therefore the amount of repetitions needed to obtain representative data.

The load-displacement data for the BL sample and the three tested conditions is shown in (Figure 3). Note the matching between the wet measurements (independent of the storage temperature) and the discrepancy of the dry measurements. The same behaviour is found for the BT samples.

The penetration depth-time and load-displacement curves were studied individually in detail. All the extracted values (mean and standard deviation) are presented in (Table 1). Although the visco-plastic creep effects seem to be slightly higher for the BT than for the BL samples, independently of the environment, the penetration depth during unloading is considerable greater in the former than in the latter condition.

The calculation of the indentation modulus depends on a fitting parameter, $m$, as described in [23]. The $m$ parameter has a physical meaning and is anticipated to be 2 for conical indenters [23]. Thus, the sensitivity of the data to this parameter was studied by comparing the results obtained with the TriboScope software supplied with the nanoindenter. ("E, GPa ( $\mathrm{m}=$ variable)" in (Table 1)) and by fixing $\mathrm{m}=2$ (“E, GPa $(\mathrm{m}=2)$ " in (Table 1)). 
The BT W indentation moduli data were the most affected by the above calculation and the corrected indentation moduli using $\mathrm{m}=2$ led to a constant difference between wet and dry measurements of $37 \%$, independent of orientation. The difference between BL W and BT W and between BL D and BT D lies around $20 \%$.

Creep effects were corrected following the method of Ngan and co-workers [24] ( $\mathrm{E}_{\text {creep }}$, (Table 1)), although creep rates at the onset of unloading were in the range of the noise of the instrument. As shown in (Table 1) there were no remarkable differences after the viscoelastic creep correction, as anticipated.

Recovery effects were more marked for the wet than for the dry conditions (Table 1). A discussion about recovery effects and nanoindentation can be found in $[25,26]$. The recovery correction proposed in $[25,26]$ was tried, but the relatively long unloading times $(10$ s) when compared with the second holding period time (20 s) and the higher recovery rates obtained for compact bone make the correction unreliable due to the extended extrapolation. Therefore, recovery was not incorporated into the calculations of the indentation modulus, although it is considered qualitatively in the interpretation and discussion of the data.

\section{Discussion}

Bushby et al. [12] found considerably differences between samples embedded in PMMA and simply immersed in fluid. Therefore, in the present study both wet and dry samples were chemically glued to the sample holder. Only the inferior surface was constrained by the sample holder, while the upper and lateral surfaces were free to deform.

Three different levels of bone hierarchical organization are thought to explain the effects of storage temperature, anisotropy effects, and environment dependence, as follows: 


\subsection{The influence of storage temperature on mechanical properties: lamellar level.}

Storage of bone at $-15^{\circ} \mathrm{C}$ for at least 12 hours does not appear to significantly influence the local indentation properties of compact lamellar bovine bone (Table 1). The $4 \%$ volume dilatation of water when frozen seems to be accommodated by the structure without producing irreversible damage. This may be explained by the multidirectional structured model of bone proposed by Ascenzi and coworkers [27] in which they stated that the spiral oriented lamellae of the osteons are able to withstand multidirectional shearing forces effectively.

Regarding moisture on the structure (beside the one filling the blood vessels, etc), not all the water surrounding collagen is thought to behave like bulk water [28, 29]. Chapman et al [28] stated that part of the hydration layer of collagen has a lower freezing point than bulk water. Moreover, water is also found in crystalline form, strongly bound to the apatite [29]. Thus, the effect of water expansion during freezing may be somewhat diminished.

Kang and coworkers [17] studied the influence of multiple thawing-freezing cycles on the indentation contact stiffness of bovine tibial cancellous bone. They found no considerably differences. Their discussion focused on the effects of freezing on the enzymatic activity, assuming the damage may come from a chemical degradation rather than a mechanical origin. Since the use of an antibacterial agent minimizes chemical degradation, in the present work, the effect of freezing the sample was evaluated from a mechanical point of view. Thus, the present work could be taken as a partially extension of the work of Kang [17] but for the case of compact bovine bone.

\subsection{Anisotropy of the same type of compact bone: fibre level.}

In the present work, while studying the influence of the environment on the mechanical properties it was found that the difference between BL W and BT W and between BL D and BT D lies around $20 \%$. This difference leads to consideration of the effect of the orientation tested on the mechanical response obtained. Zysset and coworkers [30] found a marked variability of indentation modulus 
and hardness of cortical bone taken from selected sites within an individual. Balooch [31] also observed considerably differences between cross-sections of cortical mid-femur, distal tibia, and central parietal bones of mice. Thus, in the present work, the samples were prepared from adjacent sites within the diaphysis to avoid this variability. The latter plus the specific sites tested (lamellar bone) leads us to assume that the differences in the mechanical properties stem, primarily, from the structural anisotropy of one type of bone. The same argument was used by Hoc et al. [32] in which considerable care was taken in obtaining contiguous bone samples from the same area, retrieved from a single femur.

(Figure 3) is shown to avoid the supposition of an area function calibration error associated with the measured final values. The different response of both orientations is clear.

The anisotropic trend found here is in good agreement with the measurements found in the literature $[10,16,33,34]$ and the absolute values agree within $\pm 30 \%$. The discrepancy in absolute values between those measured here may be attributed to the different origin of the samples (bovine vs human), specific environments and anatomical position.

Spears [35] developed a finite element model for enamel (the outer layer of the exposed surface of teeth) in which marked differences were predicted between the elastic modulus in the direction parallel to the enamel rod orientation (in analogy, BL orientation) and perpendicular to the enamel rod orientation (in our case, BT orientation) while considering only elastic deformation of the components. Habelitz and co-workers [36] observed anisotropy of up to $30 \%$ between the two above mentioned directions in dental enamel with a sharp (20 $\mathrm{nm}$ radius) cube corner indenter. They attributed this difference to the anisotropy and alignment of fibre-like apatite crystals within the rods and to the composite architecture of enamel. Although the micro-structural arrangement of enamel differs from compact bone [37, 38], as does the volumetric fraction of mineral (between 
0.88 and 0.91 ) the sole effect of orientation led to a factor between 2 and 3 for the elastic modulus in the direction parallel to the rod compared with the value perpendicular to the rods. Thus, as expected for enamel, the anisotropy of bone can be attributed to the arrangement of its constituents.

The organic component of bone is higher than in the case or enamel. Therefore, the higher contribution of viscous effects of the organic phase may be the reason for the particular degree of anisotropy. Although not included in the above model, for the BL indentations, the load will be mainly carried by the mineralized organic fibres which may buckle or split. On the other hand, for the BT direction, the fibres would preferentially sustain small deformations. The differences in deformation mechanisms may also lead to an anisotropy effect.

\subsection{The influence of the hydration state on mechanical properties: constituents' level.}

In the present work, the penetration depth exceeded the zone of variable contact angle of the spherical part of the indenter tip; thus at the higher loads the indentation strain was constant and directly related to the included cone angle of the indenter tip [20]. Since the loading history and the indentation strain were the same for all the conditions; and the same sample was tested under the different environments, the differences found between environments are mainly due to either genuine changes in elastic-plastic properties or to the occurrence of different deformation mechanisms depending on the tested environment.

If the arrangement between minerals and the organic matrix is simply represented by the modification of the staggered model [1,4] as shown by Gupta et al [9], then the elastic modulus of bone is given by

$$
\mathrm{E}=(1-\Phi) \mathrm{E}_{\text {matrix }}+\Phi \mathrm{E}_{\text {mineral }}\left(1+\frac{4(1-\Phi) \mathrm{D}^{2} \mathrm{E}_{\text {mineral }}}{\Phi \mathrm{L}^{2} \mathrm{G}_{\text {matrix }}}\right)^{-1} \text { Equation (1) }
$$




$$
\text { and } G_{\text {matrix }}=\frac{E_{\text {matrix }}}{2\left(1+v_{\text {matrix }}\right)}
$$

where $\Phi$ is the volume fraction of the mineral phase (hydroxyapatite), $\mathrm{E}_{\text {matrix }}$ and $\mathrm{E}_{\text {mineral }}$ are the elastic modulus of the organic phase (collagen) and of the inorganic phase (hydroxyapatite), respectively; D and $\mathrm{L}$ are the mineral thickness and length, respectively; and $v_{\text {matrix }}$ is the Poisson ratio of the organic matrix (collagen).

$\mathrm{E}_{\text {mineral }}$ is assumed to remain unchanged as it is a measure of the intrinsic modulus of the apatite component as demineralization is prevented.

By differentiating this equation with respect to $\mathrm{E}_{\text {matrix }}$ and $\phi$ and rearranging it, a relation between the relative change of total elastic modulus and the necessary relative change in elastic modulus of the matrix and the volume fraction can be obtained,

$$
\mathrm{dE}=\left[\frac{\phi^{2} \beta}{\left(\frac{\mathrm{E}_{\text {min eral }}}{\mathrm{E}_{\text {matrix }}}+\beta\right)^{2}}+(1-\phi)\right] \mathrm{dE}_{\text {matrix }}+\left[\mathrm{E}_{\text {matrix }}+\mathrm{E}_{\text {min eral }}\left(1+\frac{4(1-\phi)(\mathrm{D} / \mathrm{L})^{2} \mathrm{E}_{\text {min eral }}}{\phi \mathrm{G}_{\text {matrix }}}\right) \frac{16(\mathrm{D} / \mathrm{L})^{4} \mathrm{E}_{\text {min eral }}^{2}}{\phi^{2} \mathrm{G}_{\text {matrix }}^{2}}\right] \mathrm{d} \phi
$$

Equation (2)

$$
\text { where } \beta=\frac{8(1-\Phi)\left(1+v_{\text {matrix }}\right) D^{2}}{\Phi L^{2}}
$$

If it is assumed that $\mathrm{D} / \mathrm{L}$ (aspect ratio of the mineral platelets) $=0.03$, assuming that $\mathrm{E}$ of the mineral phase is $100 \mathrm{GPa}$ and unaffected by moisture and demineralization is prevented by HBSS and using a Poisson ratio for the organic phase of $0.25[1,39]$, and considering only elastic 
deformations are involved in the differences between wet and dry measurements, then $\mathrm{dE}$ may be estimated from the above equations. Then,

$$
\mathrm{dE}, \mathrm{GPa} \approx 0,5 \mathrm{dE}_{\text {matrix }}+175 \mathrm{~d} \phi, \text { Equation (3) }
$$

Most of the water present will fill the osteons and the remaining water will produce a change of the lateral packing of the collagen molecules of $1,5 \mathrm{~nm}$ in the wet state and $1,1 \mathrm{~nm}$ in the dry [40, 41], respectively. The above leads to an average mineral volume fraction in fibrils of $\phi \approx 0.43$ in fully mineralized cortical bone and $\phi \approx 0.56$ as the upper possible limit [1]. Therefore, $\mathrm{d} \phi$ is equal to 0,13 .

Since other phenomenological studies were not found in the literature on the effect of demineralisation on the response of the organic phase of compact bone, and due to the similar composition of dentine and bone, dentine literature has been drawn upon for the discussion. Based thus on [42-45], $\mathrm{E}_{\text {matrix }}$ of the wet demineralised matrix was chosen equal to 10-40 MPa.

Therefore, when the difference of $\mathrm{E}$ in the BL orientation between wet and dry conditions is $40 \%$, it is equivalent to a change in the elastic modulus of the organic matrix in bone, $\mathrm{dE}_{\text {matrix }}$, of $\approx$ $-65 \mathrm{GPa}$; according to Equation (2). The above leads to a $\mathrm{E}_{\text {matrix, dry }}=75$ to $105 \mathrm{GPa}$, i.e. a change of 3 to 8 times of the $E_{\text {matrix, wet. }}$

Where may this change in elastic modulus of the organic phase come from? Water is known to plasticize collagen as it is the strongest known hydrogen bonding solvent, and together with its high molar concentration ( $55 \mathrm{~mol} / \mathrm{l})$ prevents H-bonds forming between peptides of adjacent triple helices leading to a more compliant structure [46]. When drying, the absence of water molecules leaving free peptides bonds is the driving force to create new bonds between the peptide chains 
which are known to be stronger than the H-bond with water. This interpretation is supported by the observation of shrinkage of the structure upon drying [47]

The fact that the wet measurements present higher penetration depths than their dry counter parts suggests a higher compliance for the former condition. Indenting bone may contribute to wedging open and breaking the weak bonds present while using HBSS due to the imposed tensile stresses, thereby increasing the measured penetration depths and resulting in a more compliant structure. Mullins and co-workers [48] found that for Berkovich, Vickers and cube corner indenters, only the latter generated cracks in their bovine compact bone samples (The effective half cone angle of cube corner indenters is $42.28^{\circ}$, which is close to the $45^{\circ}$ half cone angle indenter used in the present work). Upon removal of the load the bonds are restored as observed with the higher viscoelastic recovery of the wet condition. The fluid environment may contribute to a higher mobility of short range bonding between neighbour collagen chain groups and, hence faster restoration of the structure. In the presence of water it seems the structure tends to form a more well ordered arrangement [49-51]. This explanation also agrees with the proposed sacrificial bond theory as found in bone $[8,52]$.

The indentation strain is the same for the case of the dry measurements; however, the reduction in water content with the consequent increment of stronger peptide bonds (which are more difficult to shear) between collagen triple helices, shrinkage of the structure and the resultant compressive state leads to a stiffer structure reflected in the lower penetration depth measured under this condition.

\section{Conclusions}

(1) The fitting $\mathrm{m}$ parameter for the unloading indentation data for determination of the E modulus using the Oliver and Pharr method [23] must be checked and corrected in order to evaluate adequately wet data of calcified tissues such as bone. 
(2) Deep freezing the samples for at least $12 \mathrm{~h}$ immersed in HBSS does not damage the structure as indicated by no change of the indentation moduli of the samples. Further studies investigating the dependence of the freezing times and cycles are warranted.

(3) The measured 20\% anisotropy between BL and BT orientation may be explained by the inherent arrangement of the constituents. The influence of the viscous properties of the organic phase may generate different deformation mechanisms during nanoindentation, and therefore modify the anisotropy ratio.

(4) The measured $40 \%$ difference in indentation modulus between wet and dry samples may be explained by a marked change in the elastic properties of the organic matrix.

(5) The change in the indentation modulus of the matrix with the chosen environment may be explained by the replacement and/or formation of inter-peptide bonds during hydration/dehydration.

\section{Acknowledgement}

Financial aid through EC Contract No MEST-CT-2004-504465, „Marie Curie Host Fellowships for Early Stage Research Training", is gratefully acknowledged. Griselda Guidoni wants to thank Dr. Himadri Gupta and Prof Peter Fratzl from Max Planck Institute of Colloids and Interfaces in Golm, Germany, for the discussions and literature given. Griselda Guidoni also kindly acknowledged Dr Markus Lengauer for the discussions and mechanical simulations provided.

\section{References}

[1] I. Jäger and P. Fratzl, Biophys. J. 79 (2000) p.1737.

[2] J. D. Currey, Bones, Princeton University Press, Princeton (USA), 2002.

[3] P. Fratzl and R. Weinkamer, Prog. Mater. Sci. 52 (2007) p.1263.

[4] H. Gao, B. Ji, I. L. Jäger, E. Arzt and P. Fratzl, P. Natl. Acad. Sci. USA 100 (2003) p.5597.

[5] Y. C. Yung, Biomechanics. Mechanical properties of living tissues, Springer Sciene+Business Media, New York (USA), 1993.

[6] W. Wagermaier, H. S. Gupta, A. Gourrier, M. Burghammer, P. Roschger and P. Fratzl, Biointerphases 1 (2006) p.1.

[7] H. S. Gupta, W. Wagermaier, G. A. Zickler, D. R.-B. Aroush, S. S. Funari, P. Roschger, H. D. Wagner and P. Fratzl, Nano Let. 5 (2005) p. 2108.

[8] J. B. Thompson, J. H. Kindt, B. Drake, H. G. Hansma, D. E. Morse and P. K. Hansma, Nature 414 (2001) p.773.

[9] H. S. Gupta, J. Seto, W. Wagermaier, P. Zaslansky, P. Boesecke and P. Fratzl, P. Natl. Acad. Sci. USA 103 (2006) p.17741.

[10] J.-Y. Rho and G. M. Pharr, J. Mater. Sci-Mater. M. 10 (1999) p.485.

[11] S. Hengsberger, A. Kulik and P. Zysset, Bone 30 ( 2002) p.178.

[12] A. J. Bushby, V. L. Ferguson and A. Boyde, J. Mat. Res. 19 (2004) p.249.

[13] H. Moscovich, N. H. J. Creugers, J. A. Jansen and J. G. C. Wolke, J. Dent. 27 (1999) p.503.

[14] M. M. Panighi, D. Allart, B. M. Jacquot, J. Camps and C. G'Sell, 13 (1997)

[15] D. B. Burr, C. H. Turner, P. Naick, M. R. Forwood, W. Ambrosius, M. S. Hasan and R. Pidaparti, 31 (1998) p.337.

[16] C. E. Hoffler, K. E. Moore, K. Kozloff, P. K. Zysset, M. B. Brown and S. A. Goldstein, Bone 26 (2000) p.603.

[17] Q. Kang, Y. H. An and R. Friedman, Am. J. Vet. Res. 58 (1997) p.1171.

[18] S. Habelitz, G. W. Marshall Jr, M. Balooch and S. J. Marshall, 35 (2002) p.995.

[19] K. L. Johnson, Contact Mechanics, Cambridge (UK), 2003.

[20] D. Tabor, Rev. Phys. Technol. 1 (1970) p.145.

[21] G. Guidoni, J. Denkmayer, T. Schöberl and I. Jäger, Phil. Mag. 86 (2006) p.5705.

[22] A. C. Fischer-Cripps, Nanoindentation, Springer-Verlag, New York (USA), 2004. 
[23] W. C. Oliver and G. M. Pharr, J. Mat. Res. 7 (1992) p.1564.

[24] A. H. W. Ngan, H. T. Wang, B. Tang and K. Y. Sze, Int. J. Solids. Struct. 42 (2005) p.1831.

[25] G. Guidoni, L. H. He, T. Schöberl, I. Jäger, G. Dehm and M. Swain, J. Mat. Res. 24 (2009) p.616.

[26] G. Guidoni, Nano-scale mechanical and tribological properties of mineralized tissues, $\mathrm{PhD}$, Montanuniversity Leoben, Leoben, Austria, 2008.

[27] M.-G. Ascenzi, A. Ascenzi, A. Benvenuti, M. Burghammer, S. Panzavolta and A. Bigid, J. Struct. Biol. 141 (2003) p.22.

[28] G. E. Chapman, S. S. Danyluk and K. A. McLauchlan, Proc. R. Soc. London B. 178 (1971) p.465.

[29] J. S. Nyman, M. Reyes and X. Wanga, Micron 36 (2005) p.566.

[30] P. K. Zysset, X. E. Guo, C. E. Hoffler, K. E. Moore and S. A. Goldstein, J. Biomech. 32 (1999) p.1005.

[31] G. Balooch, M. Balooch, R. K. Nalla, S. Schilling, E. H. Filvaroff, G. W. Marshall, S. J. Marshall, R. O. Ritchie, R. Derynck and T. Alliston, P. Natl. Acad. Sci. USA 102 (2005) p.18813.

[32] T. Hoc, L. Henry, M. Verdier, D. Aubry, L. Sedel and A. Meunier, Bone 38 (2006) p.466.

[33] Z. Fan, J. G. Swadener, J. Y. Rho, M. E. Roy and G. M. Pharr, J. Orthopaed. Res. 20 (2002) p.806.

[34] A. A. Espinoza-Orías, The relationship between the mechanical anisotropy of human cortical bone tissue and its microstructure, $\mathrm{PhD}$, Graduate School of the University of Notre Dame, Notre Dame, Indiana, 2005.

[35] I. R. Spears, J. Dental Res. 76 (1997) p.1690.

[36] S. Habelitz, S. J. Marshall, G. W. Marshall Jr and M. Balooch, Arch Oral Biol. 46 (2001) p.173.

[37] S. N. White, W. Luo, M. L. Paine, H.Fong, M. Sarikaya and M. L. Snead, J. Dental Res. 80 (2001) p.321.

[38] A. G. Fincham, J. Moradian-Oldak and J. P. Simmer, J. Struct. Biol. 126 (1999) p.270.

[39] U. Akiva, H. Wagner and S. Weiner, 33 (1998) p.1497.

[40] S. Lees, L. C. Bonar and H. A. Monk, Int. J. Biol. Macromol. 6 (1984) p.321.

[41] E. D. Eanes, D. Lundy and G. N. Martin, Calcified Tissue Int. 6 (1970) p.239.

[42] D. H. Pashley, K. A. Agee, R. M. Carvalho, K.-W. Lee, F. R. Tay and T. E. Callison, Dent. Mater. 19 (2003) p.347.

[43] K. T. Maciel, R. M. Carvalho, R. D. Ringle, C. D. Preston, C. M. Russell and D. H. Pashley, 75 (1996) p.1851.

[44] L. Angker, N. Nijhof, M. V. Swain and N. M. Kilpatrick, Eur. J. Oral Sci. 112 (2004) p.231.

[45] L. Angker, M. V. Swain and N. Kilpatrick, 38 (2005) p.1535.

[46] R. K. Nalla, M. Balooch, J. W. Ager III, J. J. Kruzic, J. H. Kinney and R. O. Ritchie, Acta Biomat. 1 (2005) p.31.

[47] D. D. Lee and M. J. Glimcher, J. Mol. Biol. 217 (1991) p.487.

[48] L. P. Mullins, M. S. Bruzzi and P. E. McHugh, 40 (2007) p.3285.

[49] Y. A. Lazarev, B. A. Grishkovsky, T. B. Khromova, A. V. Lazareva and V. S. Grechishko, Biopolymers 32 (1992) p.189.

[50] Y. A. Lazarev, B. A. Grishkovsky and T. B. Khromova, Biopolymers 24 (1985) p.1449.

[51] G. N. Ramachandran and R. Chandrasekharan, Biopolymers 6 (1968) p.1649.

[52] G. E. Fantner, T. Hassenkam, J. H. Kindt, J. C. Weaver, H. Birkedal, L. Pechenik, J. A. Cutroni, G. A. G. Cidade, G. D. Stucky, D. E. Morse and P. K. Hansma, Nature Mater. 4 (2005) p.612. 


\section{Table}

Table 1. Visco-elastic and elastic parameter obtained from the analysis of the individual loaddisplacement curves. The data are the average value followed by their standard deviation.

\begin{tabular}{|c|c|c|c|c|c|c|}
\hline & BLW & BTW & BLD & BTD & BLFR & BTFR \\
\hline $\begin{array}{c}\text { Creep rate } \\
\text { (unloading), } \mathrm{nm} / \mathrm{s}\end{array}$ & $0.09 \pm 0.2$ & $0.09 \pm 0.04$ & $0.02 \pm 0.05$ & $0.11 \pm 0.11$ & $0.06 \pm 0.05$ & $0.33 \pm 0.27$ \\
\hline Creep distance & $69 \pm 10$ & $73 \pm 14$ & $46 \pm 10$ & $66 \pm 13$ & $75 \pm 10$ & $95 \pm 17$ \\
\hline $\begin{array}{c}\text { Penetration during } \\
\text { unloading }\end{array}$ & $107 \pm 7$ & $157 \pm 43$ & $76 \pm 6$ & $101 \pm 5$ & $99 \pm 7$ & $153 \pm 14$ \\
\hline Recovery, nm & $21 \pm 8$ & $33 \pm 3$ & $15 \pm 3$ & $17 \pm 7$ & $22 \pm 3$ & $29 \pm 8$ \\
\hline $\begin{array}{c}\text { E, GPa } \\
\text { m = variable }\end{array}$ & $\begin{array}{c}23 \pm 3 \\
(2.71 \pm \\
0.32)\end{array}$ & $\begin{array}{c}16 \pm 1 \\
(3.25 \pm \\
0.25)\end{array}$ & $\begin{array}{c}32 \pm 3 \\
(2.20 \pm \\
0.20)\end{array}$ & $\begin{array}{c}25 \pm 2 \\
(2.52 \pm \\
0.22)\end{array}$ & $\begin{array}{c}24 \pm 2 \\
(2.84 \pm \\
0.27)\end{array}$ & $\begin{array}{c}16 \pm 2 \\
(3.06 \pm \\
0.40)\end{array}$ \\
\hline $\begin{array}{c}\text { E, GPa } \\
\mathbf{m}=2\end{array}$ & $23 \pm 4$ & $20 \pm 3$ & $32 \pm 3$ & $27 \pm 3$ & $27 \pm 3$ & $20 \pm 4$ \\
\hline $\begin{array}{c}\text { E creep, Gpa } \\
\mathbf{m}=2\end{array}$ & $23 \pm 4$ & $19 \pm 3$ & $32 \pm 2$ & $26 \pm 3$ & $26 \pm 3$ & $19 \pm 4$ \\
\hline $\begin{array}{l}\text { E, Gpa } \\
\text { v =0.3 }\end{array}$ & 21 & 17 & 30 & 24 & 24 & 18 \\
\hline
\end{tabular}

Creep rate (unloading): obtained by differentiating the exponential fitting of the first holding period in a displacement-time curve and calculating it at the onset of unloading.

Creep distance: average (creep) penetration during the first holding period $(5 \mathrm{mN}, 60 \mathrm{~s})$.

Penetration during unloading: penetration depth during the first partial unloading period $(0.4 \mathrm{mN} / \mathrm{s}, 10 \mathrm{~s})$.

Recovery: average viscoelastic recovery depth during the second holding period $(1 \mathrm{mN}, 20 \mathrm{~s})$.

$\mathbf{E}(\mathbf{m}=$ variable): indentation modulus calculated using the Triboscope software. Between brackets the $m$ values followed by their standard deviations are found.

$\mathbf{E}(\mathbf{m}=\mathbf{2})$ : indentation modulus calculated by manually fitting the unloading curves fixing $\mathrm{m}=2$.

E creep $(\mathbf{m}=2)$ : indentation modulus having corrected viscoelastic creep at maximum load.

$\mathbf{E}(v=\mathbf{0 . 3})$ : elastic modulus of bone considering $v=0.3$ and correcting the compliance of the indenter. 
1

2

3

4

5

6

7

8

9

10

11

12

13

14

15

16

17

18

19

20

21

22

23

24

25

26

27

28

29

30

31

32

33

34

35

36

37

38

39

40

41

42

43

44

45

46

47

48

49

50

51

52

53

54

55

56

57

58

59

60

\section{Figures' captions}

Figure 1. Schematic showing the three different defined orientations in the long compact bone tested.

Figure 2. Imaging taken using the scanning mode of the nanoindenter device. Two osteons can be observed in the lower part of the image. A group of 5 imprints are observed in one of the lamella.

Figure 3. Load-displacement curves of each individual test of the BL sample under the three different tested conditions: W, wet (under HBSS); D, dry and; FR (W) tested wet at room temperature although stored under frozen (HBSS) fluid at $-15^{\circ} \mathrm{C}$. 


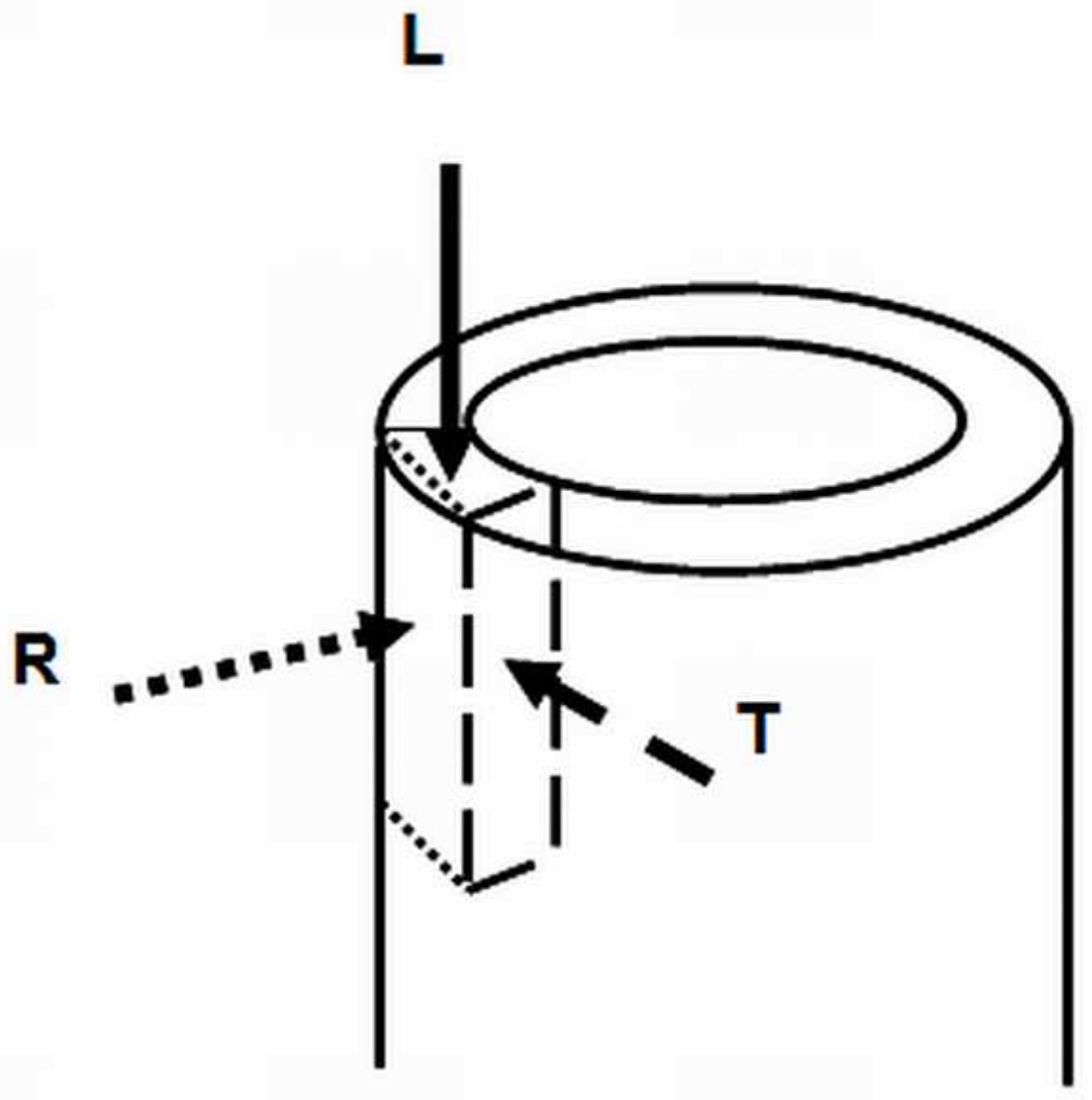

Schematic showing the three different defined orientations in the long compact bone tested. $27 \times 26 \mathrm{~mm}(600 \times 600 \mathrm{DPI})$ 
Imaging taken using the scanning mode of the nanoindenter device. Two osteons can be observed in the lower part of the image. A group of 5 imprints can be observed in one of the lamella. $436 \times 341 \mathrm{~mm}(72 \times 72 \mathrm{DPI})$ 


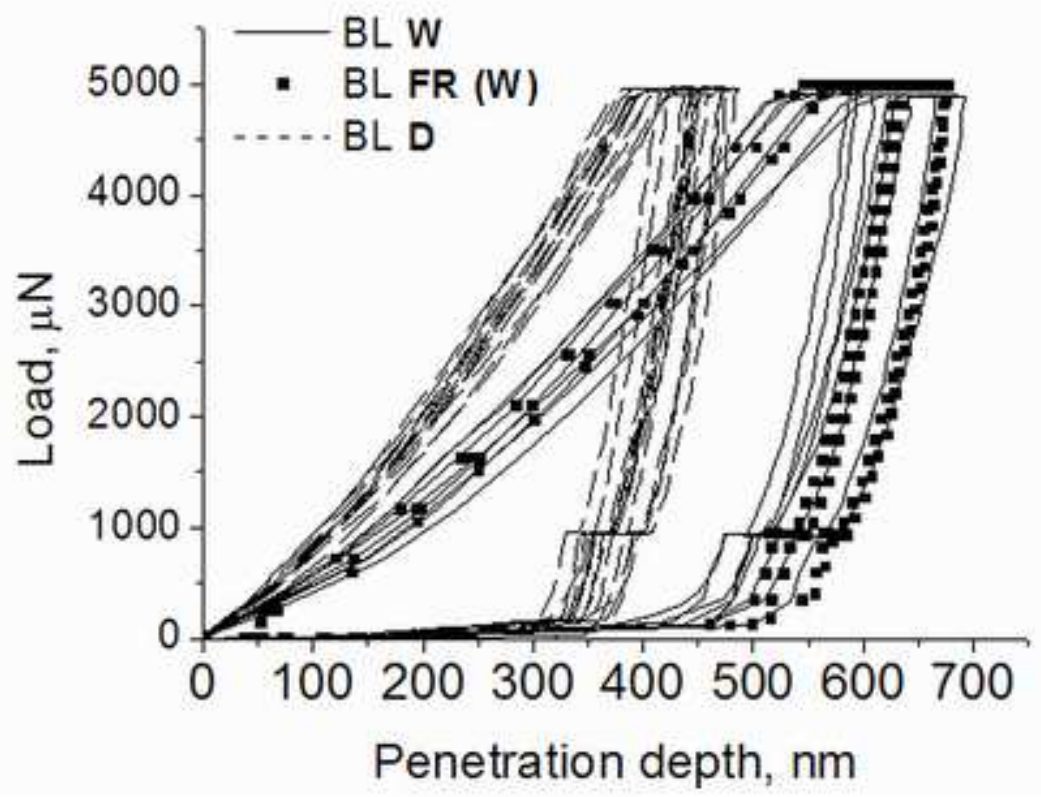

Load-displacement curves of each individual test of the $B L$ sample under the three different tested conditions: W, wet (under HBSS); D, dry and; FR (W) tested wet at room temperature although stored under frozen (HBSS) fluid at $-15^{\circ} \mathrm{C}$.

$17 \times 13 \mathrm{~mm}(600 \times 600 \mathrm{DPI})$ 